\title{
Effect of further Alloying Elements on Corrosion Resistance of Ni-Cr Alloys in Molten Glass
}

\author{
Yaxin $\mathrm{Xu}^{1}$, Jingbo Yan $^{1,2}$, Fei Sun ${ }^{1}$, Ayako Ikeda ${ }^{1}$, Yuefeng $\mathrm{Gu}^{1 *}$ \\ 1. High Temperature Materials Unit, National Institute for Materials Science (NIMS), \\ 1-2-1 Sengen, Tsukuba, Ibaraki 305-0047, Japan \\ 2. Xi'an Thermal Power Research Institute, Xingqing Road 136, Xi'an, Shaanxi \\ 710032, China \\ *:Correspondence address: \\ Prof. Yuefeng Gu \\ Address: High Temperature Materials Unit, National Institute for Materials Science \\ (NIMS) \\ 1-2-1 Sengen, Tsukuba, Ibaraki 305-0047, Japan \\ E-mail: Gu.yuefeng@nims.go.jp \\ Tel: +81-29-859-2557 \\ Fax: +81-29-859-2501
}




\begin{abstract}
The corrosion behaviour of commercial $\mathrm{Ni}-\mathrm{Cr}$ alloys added with $\mathrm{Fe}, \mathrm{Ti}, \mathrm{Nb}$ and $\mathrm{Al}$ was evaluated in molten glass at $1050{ }^{\circ} \mathrm{C}$. The static-immersion results reveal that the corrosion depth after testing for $100 \mathrm{~h}$ roughly remains at the same level for the alloys added with 5 wt.\% $\mathrm{Al}$ or added with $\mathrm{Fe}$, $\mathrm{Ti}$ and $\mathrm{Nb}$ (FeTiNb) separately, but decreases greatly by co-adding 5 wt. $\%$ Al with FeTiNb. However, a further increase of $\mathrm{Al}$ content to 15 wt. $\%$ in the co-added alloy degrades the corrosion resistance. The corrosion mechanism was discussed based on the analysis of the corrosion layer.
\end{abstract}

Keywords: A. Ni-based alloy; A. Glass; B. SEM; B. EPMA; B. XRD; C. High-temperature corrosion 


\section{Introduction}

In the glass processing industry, the corrosion issue resulting from the molten glass attack is a big challenge to the lifetime of metallic components directly in contact with the melts [1-4]. It is widely accepted that the alloys suitable for this corrosive environment should possess good resistance to oxidation and molten glass, as well as desirable mechanical strength at high temperatures $[2,5,6]$. Currently, high chromium Ni-based alloys are the most promising alloys, because they meet the basic requirement for properties $[5,7,8]$.

Over the past few years, much attentions have been attracted to the corrosion issue of Ni-Cr alloys [1, 5, 7-11]. There have been some common perspectives about the formation of protective $\mathrm{Cr}_{2} \mathrm{O}_{3}$ and the effect of $\mathrm{Cr}$ content: A chromia layer develops on pure chromium at relatively low temperatures $\left(<1025^{\circ} \mathrm{C}\right)[8]$, however, it can’t form at higher temperatures $\left(>1050{ }^{\circ} \mathrm{C}\right)$ due to the transition from a passive state to an active state [8, 12]. A similar phenomenon was observed for high chromium alloys [7]. In order to provide sufficient protection for $\mathrm{Ni}-\mathrm{Cr}$ superalloys, Rapin et al [1] proposed the method of pre-oxidation treatment or anodic protection to maintain the passive state in the case of $\mathrm{Ni}-30 \mathrm{Cr}$ immersed in $\mathrm{NC} 3 \mathrm{~S}$ at $1100{ }^{\circ} \mathrm{C}$. In addition, Lizarazu [10] reported that the corrosion rate varies with the $\mathrm{Cr}$ content in $\mathrm{Ni}-\mathrm{Cr}$ alloys. Alloys with low and high Cr-content have a corrosion rate more than a decade higher than that with intermediate $\mathrm{Cr}$-content, which is related to the different reactions referred to the alloys with various Cr-content.

It is worth to notice that, in Ni-base alloys, many alloying elements except $\mathrm{Ni}$ and $\mathrm{Cr}$ are involved due to their specific contributions to the alloy performance. For example, $\mathrm{Fe}$ is an important constituent constructing the Ni-Fe base alloy [13]. Introducing iron improves the manufacturing facility remarkably and decreases the cost at the same time. As to some strengthening constituents such as $\mathrm{Ti}, \mathrm{Nb}$, and $\mathrm{Al}$, they act as the $\gamma^{\prime}$-phase formation element to enhance the high-temperature strength of alloys $[14,15]$. The addition of above alloying elements is expected to exert a large influence on the corrosion behaviour of alloys in molten glass. Thus, it is critical to find out the role played by alloying elements in the molten-glass corrosion process at 
high temperatures. It will also be benefiting from the understanding of this knowledge for designing candidate alloys with enhanced performances that can be used in extreme conditions in future applications. However, in current literature, there are few references on this related subject. The work of Horta [16] and Abdullaha [12] deals with the Fe-Al alloy and $\mathrm{Ni}-\mathrm{Cr}-\mathrm{Al}$ alloys, respectively. However, they have opposite views on the role of $\mathrm{Al}$ in alloy corrosion. The former concluded that protective alumina layer forms during corrosion, whereas the latter reported the failure of Al-containing alloys in molten salt. With regard to other additional elements, there is extremely limited information available.

The purpose of this study is to investigate the corrosion behaviour of candidate $\mathrm{Ni}-\mathrm{Cr}$ alloys that possibly used in the molten-glass corrosive environment, thus to understand the influence of common alloying elements on the corrosion mechanism of alloys. In this paper, a series of Ni-Cr alloys with alloying elements, including Al, $\mathrm{Ti}, \mathrm{Nb}$, and $\mathrm{Fe}$ were designed and their corrosion resistance to molten glass was evaluated at $1050{ }^{\circ} \mathrm{C}$. The alloys were statically immersed in molten glass for durations up to $100 \mathrm{~h}$. The corrosion processes in the early and late stages of immersion were investigated through scanning electron microscopy (SEM) and electron probe micro-analyzer (EPMA) techniques. The corrosion mechanism for alloys with different compositions was revealed. The effect of addictive elements on the corrosion process was also examined. The present work will provide useful information for designing alloys with high performances in the glass-processing application.

\section{Materials and Experimental procedure}

In this paper, five $\mathrm{Ni}-\mathrm{Cr}$ alloys with $\mathrm{Al}, \mathrm{Fe}, \mathrm{Ti}$, and $\mathrm{Nb}$ elements were designed and investigated based on the nominal compositions as shown in Table 1. Alloy 1 (A30) is a commercial $\mathrm{Ni}-\mathrm{Cr}$ alloy, which has been widely used in the glass industry as a centrifugal spinner for fiberizing molten glass into fibers in rotary fiberizing processes. Based on the composition of A30, the other four alloys (Alloy 2 to Alloy 5) were designed with different elements, and named according to their compositions. For example, Alloy 4 (A30-5Al-FeTiNb) represents the alloy added with 5 wt. \% Al and 
combination addition of $\mathrm{Fe}, \mathrm{Ti}$ and $\mathrm{Nb}(\mathrm{FeTiNb})$. The $\mathrm{Al}$ content ranging from 5-15 wt. \% aims to improve the oxidation resistance at high temperature and to investigate the effect of $\mathrm{Al}$ on the corrosion rate in a large range. In previous work, the authors of this paper have found that the additional $\mathrm{Ti}$ and $\mathrm{Nb}$ in a proper content range enhance the high-temperature strength effectively. Therefore, in this study appropriate amount of these two elements were contained in the designed alloys. In addition, the effect of Fe element was also considered by adjusting Fe content from $\sim 6$ to 20 wt. $\%$ due to its superiority on the alloy processing and low cost. The cast ingots of these newly-developed $\mathrm{Ni}-\mathrm{Cr}$ alloys were prepared via vacuum induction melting.

The samples for corrosion test were cut into a dimension of $8 \times 10 \times 2 \mathrm{~mm}$, ground to 600\# SiC sandpaper and cleaned with ethanol ultrasonically. Each sample was placed in a $1 \mathrm{~mm}$-thick alumina crucible full filled with soda-lime glass for the glass-fiber production $\left(64.5 \% \mathrm{SiO}_{2}-0.15 \% \mathrm{Fe}_{2} \mathrm{O}_{3}-3.40 \% \mathrm{Al}_{2} \mathrm{O}_{3}-0.1 \% \mathrm{SO}_{3}-7.2 \% \mathrm{CaO}-16.0 \% \mathrm{Na}_{2} \mathrm{O}-\right.$ $1.20 \% \mathrm{~K}_{2} \mathrm{O}-4.5 \% \mathrm{~B}_{2} \mathrm{O}_{3}$ in wt. \%). The immersion test was performed at $1050{ }^{\circ} \mathrm{C}$ for durations of $5 \mathrm{~h}$ and $100 \mathrm{~h}$, respectively. When the temperature of furnace reached $1050{ }^{\circ} \mathrm{C}$, the crucibles with samples and glass were put into the furnace. After the immersion test, the crucibles were taken out of the furnace and cooled in air. Since most of the glass on sample surface has been peeled off during the cooling due to the high thermal stress, only a small amount of glass can be preserved and hence hardly observed in SEM images.

The microstructure of the raw materials and samples after corrosion test were characterized by TEOL JSM-6060 type field emission scanning electron microscopy (FE-SEM). The samples were mounted with polymer before observation, followed by grinding and polishing. The phase structure of the alloys was determined by Rigaku RINT-TTR III X-ray diffraction (XRD). In addition, EPMA was utilized to analyse the elemental distribution of alloys.

\section{Results and discussion}

\subsection{Characterization of cast alloys}

Microstructures of cast alloys under the back-scattered electron mode are presented 
in Fig.1, and their phase structures determined by XRD are shown in Fig. 2. Alloy 1 consists of $\gamma-(\mathrm{Ni}, \mathrm{Fe})$ matrix and chromium carbides along grain boundaries, the latter was identified to be $\mathrm{Cr}_{23} \mathrm{C}_{6}$ as seen in Fig. 2. Single addition of 5 wt. \% Al (Alloy 2) or FeTiNb (Alloy 3), as well as introducing both of them (Alloy 4), maintains the same major matrix of $\gamma-(\mathrm{Ni}, \mathrm{Fe})$ as Alloy 1, except for a small amount of Al-rich phase observed in Alloy 4 (Fig. d). The addition of FeTiNb produces (Nb,Ti)-rich carbide with the brightest contrast, as indicated in Fig. 1c, d, and e, which has been detected in the XRD patterns in Fig. 2. Different from the above alloys, high Al content of 15 wt. \% leads to a transition of phase structure from $\gamma$-(Ni,Fe) to a homogeneous mixture of dark Al-rich phase and light $(\mathrm{Fe}, \mathrm{Cr})$-rich phase, with dispersed $(\mathrm{Nb}, \mathrm{Ti}) \mathrm{C}$ particles as well as some $\mathrm{Cr}_{23} \mathrm{C}_{6}$ in Alloy 5 (Fig. 1e).

The results of XRD pattern are consistent with the microstructure observed by SEM in Fig. 1. Alloys 1 to 4 has the same structure of $\gamma-(\mathrm{Ni}, \mathrm{Fe})$. No Al-rich phase was detected when $\mathrm{Al}$ content is at a low level (Alloys 2 and 4). Based on the above results, it can be inferred that, $5 \mathrm{wt}$ \% $\mathrm{Al}$ does not change the major phase structure, and increasing Fe content from 6 to 20 wt. \% has the similar effect, however, high Al content promotes the formation of $\mathrm{NiAl}$ phase.

\subsection{Microstructures of alloys after molten glass corrosion}

Figure 3 shows the SEM images in the back-scattered electron mode of alloys after glass corrosion at $1050{ }^{\circ} \mathrm{C}$ for $5 \mathrm{~h}$ and $100 \mathrm{~h}$, respectively. The results at the initial stage of immersion give useful information about where corrosion begins. It is clear that, commercial Alloy 1 shows a typical characteristic of glass attack along the $\mathrm{Cr}$-rich phase (dark), since the corrosion voids elongate in the direction where $\mathrm{Cr}_{23} \mathrm{C}_{6}$ precipitate, as indicated by the arrows in Fig. 3a. Similar to Alloy 1, Alloy 3 with $\mathrm{FeTiNb}$ exhibits the same corrosion feature preferentially along chromium carbides (Fig. 3e). Conversely, the corrosion voids seem to be dispersed more randomly on the surface of Alloy 3 with 5Al addition (Fig. 3c). By adding 5 wt. \% $\mathrm{Al}$ and FeTiNb together, Alloy 4 forms a surface Nb-rich layer, with a thickness of $\sim 1 \mu \mathrm{m}$ after $5 \mathrm{~h}$ immersion (Fig. 3g), which is not present in other cases. In terms of high Al Alloy 5, 
selective corrosion proceeds at the NiAl phase (Fig. 3i). Massive dissolution occurs to the $\mathrm{NiAl}$ constituent, leaving the skeleton of $(\mathrm{Fe}, \mathrm{Cr})$ phase.

After $100 \mathrm{~h}$ immersion, molten glass penetrates deeper into the base alloys, and there are no new features present except for the thickening of surface corrosion layer in comparison with the early stage. The alloy dissolution makes the surface layer porous to varying extents. It is notable that, Alloy 4 and Alloy 5 suffer from the least and the most corrosion attacks among all alloys, respectively, and the other three alloys are in a relatively medium level of corrosion. The Nb-rich layer is still present on the surface of Alloy 4, affording sufficient protection for the base alloy. In contrast, plenty of corrosion pores can be observed for Alloy 5, and the outermost layer of which has hardly adhesion with the subscale. In addition, the Cr-rich or Al-rich phases initially present on the near-surface layer have disappeared after $100 \mathrm{~h}$ in all cases.

The average corrosion depth of alloys after immersion for $100 \mathrm{~h}$ was measured using SEM images, taken from 6 different regions for each sample, and the averages along with standard deviations are shown in Table 2. The commercial Alloy 1 corrodes for $\sim 75.7 \mu \mathrm{m}$ thick after $100 \mathrm{~h}$, and Alloy 2 with $5 \mathrm{Al}$ and Alloy 3 with FeTiNb yield the values of $\sim 70.8 \mu \mathrm{m}$ and $71.0 \mu \mathrm{m}$, respectively, roughly at the same level with Alloy 1. Alloy 4 possesses superior corrosion resistance because of the smallest corrosion depth of $\sim 17.8 \mu \mathrm{m}$, as a contrast, the value for Alloy 5 is as high as $\sim 81.3 \mu \mathrm{m}$.

Based on the above results, it is clear that the individual addition of $5 \mathrm{wt}$ \% $\mathrm{Al}$, or FeTiNb does not degrade the corrosion behaviour of Alloy 1. However, rather surprisingly, when combining the above additions to form Alloy 4, it has an excellent positive effect on improving the resistance to glass attack with the formation of $\mathrm{Nb}$-rich layer. Nevertheless, a further increase of $\mathrm{Al}$ content up to 15 wt. $\%$ is apparently favouring the corrosion of $\mathrm{NiAl}$ phase with a negative effect on the corrosion resistance.

\subsection{Characterization of the phase structure and element distribution}

Figure 4 shows the XRD patterns of alloys after corrosion for $100 \mathrm{~h}$ in molten glass 
at $1050{ }^{\circ} \mathrm{C}$. Alloy 1 to 3 shows the same phase structure of $\gamma-(\mathrm{Ni}, \mathrm{Fe})$ as the cast alloys in Fig. 2, indicating no protective product develops for these three alloys, which is consistent with the microstructure observed in Fig. 3. The disappearance of carbides peaks is due to the dissolution of Cr-carbide on the surface layer. $\mathrm{Nb}_{6} \mathrm{Ni}_{16} \mathrm{Si}_{7}$ is detected on Alloy 4, which corresponds to the Nb-rich phase observed in Fig. 3g and 3h. $\mathrm{Cr}_{6.5} \mathrm{Ni}_{2.5} \mathrm{Si}$ forms on Alloy 5 with high $\mathrm{Al}$ content. Since there is no silicon in Alloys 4 and 5, the Si-containing compound is believed to be resulting from the reduction of $\mathrm{SiO}_{2}$ in glass $[1,17]$.

In order to further explore the corrosion process during immersion, EPMA mapping of cross sections of alloys was conducted, and the elemental distribution is shown in Figures 5 to 9 . Figure 5 gives the mapping result of Alloy 1 (A30), it can be seen that the aggressive molten glass tends to attack Cr-rich constituent first because the corrosion voids caused by dissolution are along the locations where carbides precipitated. Furthermore, significant Cr-depletion layer of $\sim 75 \mu \mathrm{m}$ thick is also observed in Fig. 5b, whereas such an impoverishment is not observed for the other constituents. Within the same region where $\mathrm{Cr}$ is depleted, silicon is found to be concentrated as seen from the Si profile in Fig. 5e, which comes from the glass by the reduction reaction [12]. Thus, the damage of Alloys 1 is driven primarily by the selective dissolution of $\mathrm{Cr}$.

The EPMA mapping results of Alloy 2 with 5Al addition are displayed in Fig. 6. Al profile in Fig. $6 \mathrm{~b}$ reveals an Al-depletion layer with a thickness of $\sim 95 \mu \mathrm{m}$, while the value of the Cr-depletion layer is only $\sim 63 \mu \mathrm{m}$ (Fig. 6c), owing to the much lower $\mathrm{Al}$ content (5 wt. \%) than $\mathrm{Cr}(26 \mathrm{wt} . \%)$ in the original alloy. This result indicates both $\mathrm{Al}$ and $\mathrm{Cr}$ participate in the corrosion process. It needs to be noticed that the shapes and distribution of corrosion voids are no longer in accordance with the Cr-rich phase in the far field alloy, that is, they are prone to distribute more uniformly compared with previous Alloy 1. Moreover, by adding 5 wt. \% Al into Alloy 1, the Cr depletion on surface layer has been weakened (Fig. 6c), which can be distinguished from the thickness and the steepness of colour change within the Cr-depleted layer compared with that in Fig. 5b. Therefore, it is reasonable to infer that the corrosion of $\mathrm{Cr}$ is 
limited by $\mathrm{Al}$ dissolution to some extent.

Figure 7 presents the mapping results of Alloy 3 with alloyed FeTiNb. Cr is found to be critically depleted in corrosion layer along the chromium carbides (Fig. 7b), the same as Alloy 1. Although 20 wt. \% Fe was introduced to this alloy, no evidence of massive corrosion to Fe element is observed (Fig. 7c), which is possibly related to the higher stability of $\mathrm{Fe}$ than $\mathrm{Cr}$ in molten glass as indicated in previous work [8]. $\mathrm{Nb}$ and $\mathrm{Ti}$ are observed to be slightly depleted near the surface layer as seen in Fig. $7 \mathrm{~g}$ and Fig. 7h. Comparing the profiles of $\mathrm{Nb}$ (Fig. 7h) and $\mathrm{Cr}$ (Fig. 7b), it can be inferred that $\mathrm{Cr}$-rich carbide is more likely to be corroded than $\mathrm{Nb}$, due to the thinner depletion layer of $\mathrm{Nb}$. On basis of the results in Fig. 5 and 7, the addition of FeTiNb in Alloy 1 has no significant effect on the element distribution during the corrosion, and both Alloy 1 and Alloy 3 exhibit the typical Cr-dissolution induced alloy failure.

The results of Alloy 4 with combined FeTiNb and 5Al addition are given in Fig. 8 . The thickness of the Al-depletion layer is $\sim 75 \mu \mathrm{m}$ (Fig. $8 \mathrm{~b}$ ), much thinner than that of Alloy 2 with 5Al. Meanwhile, the $\mathrm{Cr}$ seems to be immune from the glass corrosion (Fig. 8c). Although the dissolution of Cr-rich phase still occurs, the areas not containing Cr-rich precipitates exhibit the same colour intensity as that in base alloy. Moreover, a layer rich in $\mathrm{Nb}, \mathrm{Ni}$, and $\mathrm{Si}$ is observed at the interface of alloy/glass (Fig. $8 \mathrm{e}, \mathrm{h}$ and i). This is completely in accordance with the microstructure and XRD results in Fig. 3 and Fig. 4. The contrast between the corrosion behaviour of Alloy 2 and Alloy 4 is probably owing to the formation of this $\mathrm{Nb}_{6} \mathrm{Ni}_{16} \mathrm{Si}$ layer. In the case of Alloy 4, the dissolution of active $\mathrm{Al}$ and $\mathrm{Cr}$ are both inhibited, which is proved by the results in Fig. $8 \mathrm{~b}$ and c.

The mapping results of Alloy 5 with $15 \mathrm{Al}$ and FeTiNb are shown in Fig. 9. It can be observed that corrosion occurs in a totally different way with respect to Alloy 1 to 4: the surface of Alloy 5 dissolves severely, producing a rather loose corrosion layer of $\sim 79 \mu \mathrm{m}$ with substantial pores. No $\mathrm{Nb}_{6} \mathrm{Ni}_{16} \mathrm{Si}_{7}$ layer is present, which is in agreement with the XRD results in Fig. 4. Since the NiAl phase is confirmed to be dissolved first in Section 3.1, the depletion for $\mathrm{Al}$ and $\mathrm{Ni}$ is both observed in mapping results (Fig. 9b and Fig. 9e). Another distinct feature is that there is hardly 
impoverishment in Cr profile (Fig. 10c), instead, the surface is rich in chromium. This indicates that the corrosion of Alloy 5 is predominated by the dissolution of Al-rich phase. In turn, $\mathrm{Cr}$ is almost restrained from corrosion.

In addition to $\mathrm{Al}$ and $\mathrm{Cr}, \mathrm{Ti}$ is another active element at high temperatures. In this study, the alloys with $0.5 \mathrm{wt} . \%$ Ti (Alloy 3, 4 and 5) exhibit a slight Ti depletion to various extents, which can be observed from the Ti profiles of EPMA as shown in Fig. $7 \mathrm{~g}, 8 \mathrm{~g}$ and $9 \mathrm{~g}$, suggesting that Ti has relatively high activity and is expected to dissolve in glass like $\mathrm{Al}$ and $\mathrm{Cr}$. Except for such a trend of active dissolution, there is no evidence of the interaction between $\mathrm{Ti}$ and $\mathrm{Nb}_{6} \mathrm{Ni}_{16} \mathrm{Si}_{7}$ surface layer, or other distinct corrosion characteristics. Therefore, Ti seems not to change the corrosion mechanism. In view of the low level of $\mathrm{Ti}$ content in this study, the role of $\mathrm{Ti}$ in the corrosion process can be negligible in the composition range of 0-0.5 wt. \%. However, if the content of Ti in the alloy increases to some critical value, the impact of Ti should also be considered.

\subsection{Corrosion mechanism}

Based on the above results, the alloying elements of $\mathrm{Fe}, \mathrm{Al}, \mathrm{Ti}$, and $\mathrm{Nb}$ have individually variable, or even interaction effect on the corrosion behaviour of $\mathrm{Ni}-\mathrm{Cr}$ alloys. The corrosion mechanism can be illustrated schematically in Fig. 10. The first mechanism for alloys without $\mathrm{Al}$ addition is presented in Fig. 10a. Corrosion begins at the locations where Cr-rich carbides precipitate at the early stage of corrosion. In the late stage, further penetration of molten glass occurs along the pores produced by the dissolution of chromium carbides. The reactions at the alloy/glass interface are the oxidation of $\mathrm{Cr}$ and the reduction of $\mathrm{SiO}_{2}$ from the network in glass, which can be written as the following equations [18-20]:

$$
\begin{gathered}
\mathrm{Cr} \rightarrow \mathrm{Cr}^{2+}+2 \mathrm{e} \\
\mathrm{SiO}_{4}^{4-}+4 \mathrm{e} \rightarrow \mathrm{Si}^{0}+40^{2-}
\end{gathered}
$$

From the above results, it can be inferred that both Alloy 1 and 3 follow this corrosion process. Therefore, the FeTiNb has no apparent influence on the corrosion mechanism. 
The second mechanism aims to explain the corrosion of alloys with the minor $\mathrm{Al}$ content as seen in Fig. 10b. For Alloy 2 with 5 wt. \% Al, aluminium participates in the corrosion together with chromium. According to our previous work on Ni-base alloys with $\mathrm{Al}$ addition, $\mathrm{Al}$ is more likely to dissolve in molten glass due to its higher chemical activity than $\mathrm{Cr}$, which has also been proved by other investigations $[12,21]$. As a consequence, the existence of $\mathrm{Al}$ in alloys makes itself corroded preferentially, furthermore, the attack aiming at chromium is inhibited to some extent. Thus, the corrosion tends to proceed uniformly in Alloy 2. In this case, the corrosion reactions are the oxidation of both $\mathrm{Al}$ (Eq. 3) and $\mathrm{Cr}$, together with the reduction of $\mathrm{SiO}_{2}$. Even though the corrosion of $\mathrm{Al}$ proceeds much faster than that of $\mathrm{Cr}$, the corrosion rate obtained by corrosion depth still maintains at the same level with Alloy 1 without $\mathrm{Al}$ (Fig. 3). This is because the corrosion in this case is controlled by the diffusion of $\mathrm{Al}$ from the base alloy to the interface, due to the limited $\mathrm{Al}$ content. For this reason, the minor $\mathrm{Al}$ addition is helpful to improve the corrosion resistance of $\mathrm{Ni}-\mathrm{Cr}$ alloy, which has been reported in previous work.

Figure 10c explains the corrosion process of Alloy 4 with $5 \mathrm{Al}$ and FeTiNb, a protective layer of $\mathrm{Nb}_{6} \mathrm{Ni}_{16} \mathrm{Si}_{7}$ starts to form on the alloy surface at initial stage of corrosion, the presence of which inhibits the diffusion of reactant and product species across the reaction interface. As a result, the corrosion of $\mathrm{Al}$ and $\mathrm{Cr}$ is significantly mitigated. Since it is not entirely continuous, slight corrosion still takes place in the underlying alloy, however, with a much thinner corrosion layer. Theoretically, the dissolution of $\mathrm{Nb}_{6} \mathrm{Ni}_{16} \mathrm{Si}_{7}$ occurs spontaneously along with its formation in molten glass at high temperature, and the durability of this film depends on the competition between these two processes. After $100 \mathrm{~h}$ immersion, the $\mathrm{Nb}_{6} \mathrm{Ni}_{16} \mathrm{Si}_{7}$ layer is still protective for Alloy 4, indicating that the solubility of $\mathrm{Nb}_{6} \mathrm{Ni}_{16} \mathrm{Si}_{7}$ in glass is relatively small and the formation prevails in the dissolution process over $100 \mathrm{~h}$ duration.

Figure 10d illustrates the corrosion of high $\mathrm{Al}$ alloy. When the $\mathrm{Al}$ content increases to $15 \mathrm{wt} . \%$, the $\mathrm{NiAl}$ phase undergoes selective corrosion in molten glass. Along with the massive dissolution of Al-rich phase, the surface layer becomes loose, porous and discrete, losing the diffusion paths for $\mathrm{Nb}$ access to the surface. Therefore, $\mathrm{Nb}$-rich 
phase is dispersed in the alloy, instead of enriching on the surface. In addition, the dissolution of $\mathrm{Al}$ proceeds according to the interface reaction of Eq. 3 without diffusion-controlled process, due to the sufficient Al content (15 wt. \%) supplied by high Al substrate, which is proved by the absence of surface Al-depletion layer. As a result, Alloy 5 corrodes rapidly with the highest corrosion depth as shown in Table 2. Meanwhile, the corrosion of chromium element is almost retarded due to its relatively low activity with respect to $\mathrm{Al}$.

$$
\mathrm{Al} \rightarrow \mathrm{Al}^{3+}+3 \mathrm{e}
$$

It is clear that the $\mathrm{Nb}_{6} \mathrm{Ni}_{16} \mathrm{Si}_{7}$ layer is important to protect the alloy from the molten-glass dissolution process and this layer only forms when a small amount of $\mathrm{Al}$ is introduced to $\mathrm{Nb}$-added alloys. The possible explanation for this phenomenon is that the addition of $\mathrm{Al}$ changes the dissolution mode of $\mathrm{Ni}-\mathrm{Cr}$ alloys from a chromium-preferring one to a relatively uniform one, leading to the increase in diffusion paths for $\mathrm{Nb}$ to the surface. As is known that, grain boundaries provide the short diffusion paths of elements due to the high energy at these locations [22, 23]. From the mapping results of Alloy 3 in Fig. 7, it can be observed that $\mathrm{NbC}$ enriches mainly at the grain boundaries together with $\mathrm{Cr}$ carbides. When the glass penetrates inward and dissolves the Cr-rich carbides at grain boundaries, the outer-diffusion paths of $\mathrm{Nb}$ are destroyed. For this reason, $\mathrm{Nb}$ enrichment is not observed on Alloy 3. By adding $\mathrm{Al}$ into $\mathrm{Ni}-\mathrm{Cr}$ alloy, the attack to $\mathrm{Cr}$-rich carbides transfers to $\mathrm{Al}$ element and the corrosion no longer takes place merely along the grain boundaries. As a result, these diffusion routes are partially preserved and $\mathrm{Nb}$ has access to concentrate on the surface. This hypothesis is supported by the apparent evidence of corrosion voids along Cr-rich carbides for Alloy 1 and 3 (no $\mathrm{Al}$ addition), which becomes less distinct in the case of Alloy 2 and 4 containing minor Al. However, the knowledge of the durability and the factors that promote $\mathrm{Nb}_{6} \mathrm{Ni}_{16} \mathrm{Si}_{7}$ generation still needs further investigations, which would be focused in our future work.

\section{Conclusions}

In this study, the corrosion behaviour of a commercial $\mathrm{Ni}-\mathrm{Cr}$ alloy with different 
alloying elements in molten glass at $1050{ }^{\circ} \mathrm{C}$ was investigated. Results indicate that:

1. The molten glass mainly attacks the Cr-rich carbide along grain boundaries in commercial Ni-Cr alloy;

2. The addition of FeTiNb has little influence on the corrosion behaviour of alloy;

3. Individual addition of 5wt. \% Al results in the dissolution of both $\mathrm{Al}$ and $\mathrm{Cr}$, changing the corrosion mode from a selective corrosion along chromium carbides to a uniform corrosion;

4. The alloy with co-added 5 wt. $\% \mathrm{Al}$ and FeTiNb has the highest corrosion resistance among investigated alloys due to the formation of a protective $\mathrm{Nb}_{6} \mathrm{Ni}_{16} \mathrm{Si}_{7}$ layer;

5. Excessive Al content of $15 \mathrm{wt} \%$ has a detrimental effect on the corrosion resistance.

\section{Acknowledgement}

This work was supported by the National Science Foundation of China [grant numbers 51301131].

\section{References:}

[1] T.K. Abdullah, C. Petitjean, P.J. Panteix, E. Schmucker, C. Rapin, M. Vilasi, Corrosion of Pure Cr and Ni-30Cr Alloy by Soda-Lime-Silicate Melts: Study of Simplified Systems, Oxid. Met. 85 (2016) 3-16.

[2] S.K. Sundaram, R.F. Speyer, Electrochemical corrosion and protection of molybdenum and molybdenum disilicide in a molten soda-lime silicate glass environment, J. Am. Ceram. Soc. 79 (1996) 1851-1856.

[3] A. Littner, B.G. Allemand, M. Francois, M. Vilasi, Molten glass corrosion resistance of $\mathrm{Mo}_{\mathrm{x}} \mathrm{Ru}_{\mathrm{y}} \mathrm{Si}_{\mathrm{z}}$ compounds at 1350 degrees $\mathrm{C}$ in an alkali borosilicate glass, Corros. Sci. 48 (2006) 1426-1436.

[4] G. Luo, J. Li, Q. Shen, D. Zhang, L. Zhang, Corrosion behaviour of tin dioxide based electrode material at high temperature in molten soda-lime-silicate glass, Corros Sci, 50 (2008) 591-595. 
[5] A. Carton, C. Rapin, R. Podor, P. Berthod, Corrosion of chromium in glass melts, J. Electrochem. Soc., 153 (2006) B121-B127.

[6] R. Podor, N. David, C. Rapin, M. Vilasi, P. Berthod, Mechanisms of corrosion layer formation during zirconium immersion in a (Fe)-bearing glass melt, Corros. Sci. 49 (2007) 3226-3240.

[7] J. Di Martino, C. Rapin, P. Berthod, R. Podor, P. Steinmetz, Corrosion of metals and alloys in molten glasses. Part 2: nickel and cobalt high chromium superalloys behaviour and protection, Corros. Sci. 46 (2004) 1865-1881.

[8] J. Di Martino, C. Rapin, P. Berthod, R. Podor, P. Steinmetz, Corrosion of metals and alloys in molten glasses. Part 1: glass electrochemical properties and pure metal (Fe, Co, Ni, Cr) behaviours, Corros. Sci. 46 (2004) 1849-1864.

[9] P. Steinmetz, C. Rapin, Corrosion of high temperature alloys by molten glass, in: R. Streiff, I.G. Wright, R.C. Krutenat, M. Caillet, A. Galerie (Eds.) High Temperature Corrosion and Protection of Materials 5, Pts 1 and 2, 2001, pp. 865-872.

[10] D. Lizarazu, P. Steinmetz, J.L. Bernard, Corrosion of nickel-chromium alloys by molten glass at 1100 degrees C: An electrochemical study, in: R. Streiff, J. Stringer, R.C. Krutenat, M. Caillet, R.A. Rapp (Eds.) High Temperature Corrosion and Protection of Materials 4, Pts 1 and 2, 1997, pp. 709-719.

[11] C. Rapin, M. Vilasi, R. Podor, A. Carton, B. Gaillard-Allemand, P. Berthod, P. Steinmetz, p. trans tech, Three examples of high-temperature corrosion of metals by molten glasses, in: P. Steinmetz, I.G. Wright, G. Meier, A. Galerie, B. Pieraggi, R. Podor (Eds.) High Temperature Corrosion and Protection of Materials 6, Prt 1 and 2, Proceedings, 2004, pp. 1125-1132.

[12] T.K. Abdullaha, C. Petitjean, P.-J. Panteix, S. Mathieu, C. Rapin, M. Vilasi, Z. Hussain, A.A. Rahim, Electrochemical characterization of chromia- and alumina-forming nickel-based superalloys in molten silicates, Appl. Surf. Sci. 360 (2016) 510-518.

[13] R.C. Reed, The Superalloys: Fundamentals and Applications, Cambridge University Press, 2008.

[14] A.K. Jena, M.C. Chaturvedi, The role of alloying elements in the design of 
nickel-base superalloys, J. Mater. Sci. 19 (1984) 3121-3139.

[15] T.M. Pollock, S. Tin, Nickel-Based Superalloys for Advanced Turbine Engines: Chemistry, Microstructure and Properties, J. Propul. Power 22 (2006) 361-374.

[16] A. Hotar, V. Hotar, F. Novotny, Corrosion behaviour of Fe-40Al-Zr (at.\%) alloy in molten soda-lime glass, Kovove. Mater. 52 (2014) 149-155.

[17] Y. Miura, K. Takahashi, Electrode reactions of various electric conductive materials in some molten glasses, J. Non-Cryst. Solids 38-39, Part 1 (1980) $347-352$.

[18] T.M. Besmann, K.E. Spear, Thermochemical modeling of oxide glasses, J. Am. Ceram. Soc. 85 (2002) 2887-2894.

[19] K. Takahashi, Y. Miura, Electrochemical studies on ionic behavior in molten glasses, J. Non-Cryst. Solids 80 (1986) 11-19.

[20] K. Matusita, M. Satou, T. Komatsu, T. Nakahara, A. Nitta, Interface reaction between oxide glasses and Fe-Al-Si magnetic alloy, J. Mater. Sci. 28 (1993) 6333-6339.

[21] M. Nath, A. Ghosh, H.S. Tripathi, Hot corrosion behavior of $\mathrm{Al}_{2} \mathrm{O}_{3}-\mathrm{Cr}_{2} \mathrm{O}_{3}$ refractory by molten glass at $1200{ }^{\circ} \mathrm{C}$ under static condition, Corros. Sci. 102 (2016) 153-160.

[22] W. Wei, Z. Wang, M. Liu, The impact of grain size on oxidation behavior of TP304H austenitic stainless steel at high temperature in air, in: H.X. Zhang, Y. Han, F. Chen, J. Wen (Eds.) Materials and Computational Mechanics, Pts 1-3, 2012, pp. 990-994.

[23] V.B. Trindade, U. Krupp, P.E.G. Wagenhuber, H.J. Christ, Oxidation mechanisms of Cr-containing steels and Ni-base alloys at high-temperatures - Part I: The different role of alloy grain boundaries, Materials and Corrosion-Werkstoffe Und Korrosion 56 (2005) 785-790. 


\section{Figure captions and Tables:}

Fig. 1 Microstructures of the cast alloys: (a) Alloy 1 (A30), (b) Alloy 2 (A30-5Al), (c) Alloy 3 (A0-FeTiNb), (d) Alloy 4 (A30-5Al-FeTiNb), (e) Alloy 5 (A30-15Al-FeTiNb) Fig. 2 XRD patterns of the cast alloys

Fig. 3 Cross section (SEM-BEI) of alloys after immersion in molten glass at $1050{ }^{\circ} \mathrm{C}$ for $5 \mathrm{~h}$ and 100 h: (a,b) Alloy 1, (c,d) Alloy 2, (e,f) Alloy 3, (g,h) Alloy 4, (i, j) Alloy 5 Fig. 4 XRD patterns of alloys after molten glass corrosion at $1050{ }^{\circ} \mathrm{C}$ for $100 \mathrm{~h}$ Fig. 5 EPMA mapping results of Alloy 1 after molten glass corrosion at $1050{ }^{\circ} \mathrm{C}$ for $100 \mathrm{~h}$

Fig. 6 EPMA mapping results of Alloy 2 after molten glass corrosion at $1050{ }^{\circ} \mathrm{C}$ for $100 \mathrm{~h}$

Fig. 7 EPMA mapping results of Alloy 3 after molten glass corrosion at $1050{ }^{\circ} \mathrm{C}$ for $100 \mathrm{~h}$

Fig. 8 EPMA mapping results of Alloy 4 after molten glass corrosion at $1050{ }^{\circ} \mathrm{C}$ for $100 \mathrm{~h}$

Fig. 9 EPMA mapping results of Alloy 5 after molten glass corrosion at $1050{ }^{\circ} \mathrm{C}$ for 100 $\mathrm{h}$

Fig. 10 Schematic diagrams of corrosion mechanism for Ni-Cr alloys: (a) without $\mathrm{Al}$; (b) with low levels of $\mathrm{Al}$ (5 wt.\%); (c) with 5 wt.\% $\mathrm{Al}$ and FeTiNb; (d) with 15 wt.\% $\mathrm{Al}$ and FeTiNb 
Table 1 The composition of alloys in mass percentage

\begin{tabular}{|c|c|c|c|c|c|c|c|}
\hline \multirow{2}{*}{ Alloy } & \multicolumn{7}{|c|}{ Composition (wt. \%) } \\
\hline & $\mathrm{Cr}$ & $\mathrm{Al}$ & $\mathrm{Fe}$ & $\mathrm{Ti}$ & $\mathrm{Nb}$ & Others & $\mathrm{Ni}$ \\
\hline 1 & 28 & - & 6.0 & - & - & C:0.7, Si:0.6 & Bal. \\
\hline (A30) & & & & & & $\mathrm{W}: 7.4$ & \\
\hline 2 & 26 & 5 & 5.7 & - & - & $C: 0.66$ & Bal. \\
\hline (A30-5Al) & & & & & & W:7.03 & \\
\hline 3 & 25 & - & 20 & 0.5 & 1.5 & $C: 0.69$ & Bal. \\
\hline (A30-FeTiNb) & & & & & & W:7.25 & \\
\hline 4 & 25 & 5 & 20 & 0.5 & 2.0 & $C: 0.64$ & Bal. \\
\hline (A30-5Al-FeTiNb) & & & & & & W:6.81 & \\
\hline 5 & 25 & 15 & 20 & 0.5 & 2.0 & $C: 0.63$ & Bal. \\
\hline (A30-15Al-FeTiNb) & & & & & & W:6.66 & \\
\hline
\end{tabular}

Table 2 The average corrosion depth of alloys after corrosion in molten glass at $1050{ }^{\circ} \mathrm{C}$ for $100 \mathrm{~h}$

\begin{tabular}{cccccc}
\hline Alloy No. & 1 & 2 & 3 & 4 & 5 \\
\hline $\begin{array}{c}\text { Corrosion depth } \\
(\mu \mathrm{m}) \pm \mathrm{SD}^{*}(\mu \mathrm{m})\end{array}$ & $75.7 \pm 6.6$ & $70.8 \pm 6.0$ & $71.0 \pm 5.5$ & $17.8 \pm 1.5$ & $81.3 \pm 4.8$ \\
\hline
\end{tabular}

*SD refers to the standard deviation of values extracted from different areas. 

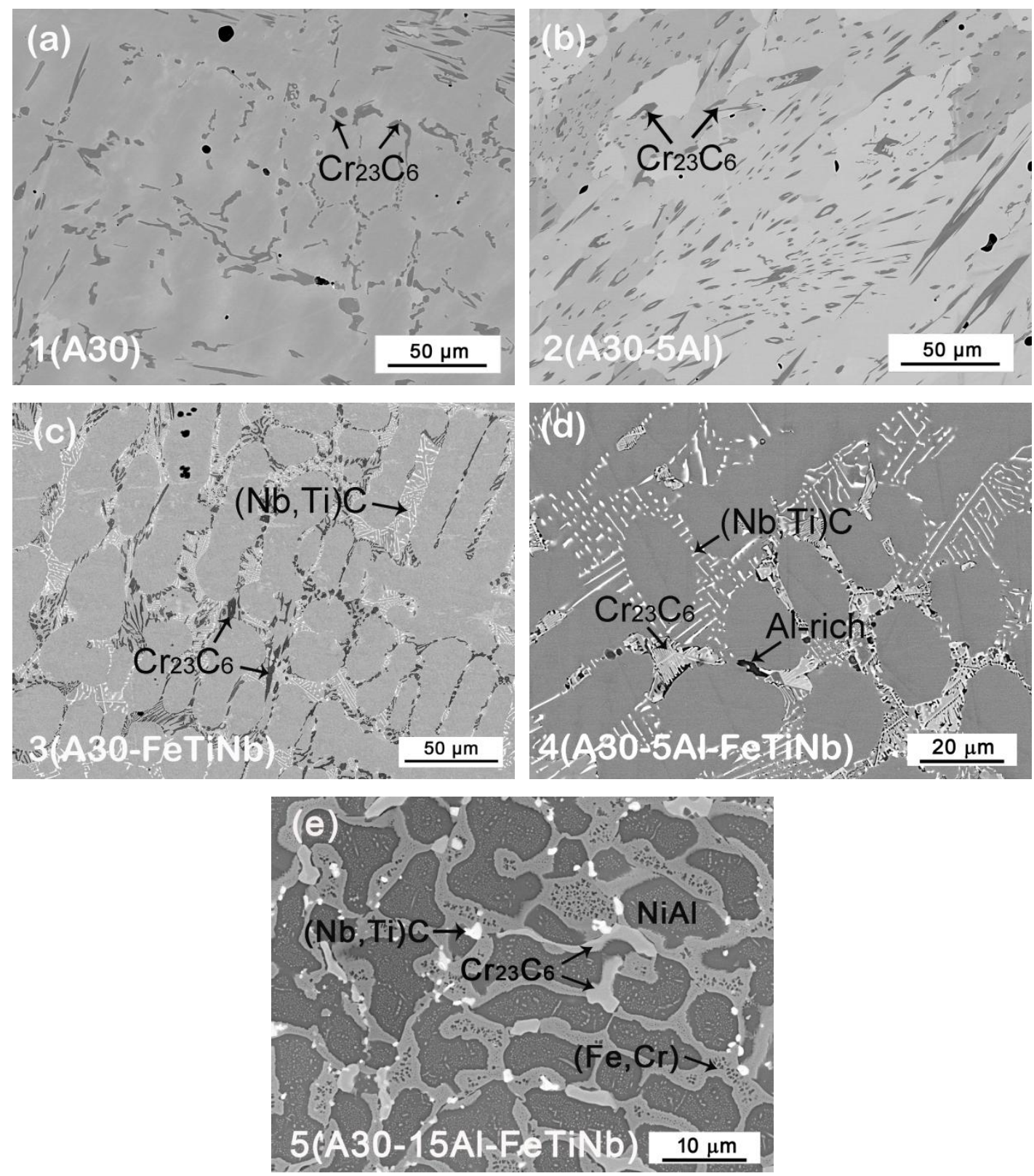

Fig. 1 Microstructures of the cast alloys: (a) Alloy 1 (A30), (b) Alloy 2 (A30-5Al), (c) Alloy 3(A30FeTiNb), (d) Alloy 4 (A30-5Al-FeTiNb), (e) Alloy 5 (A30-15Al-FeTiNb) 


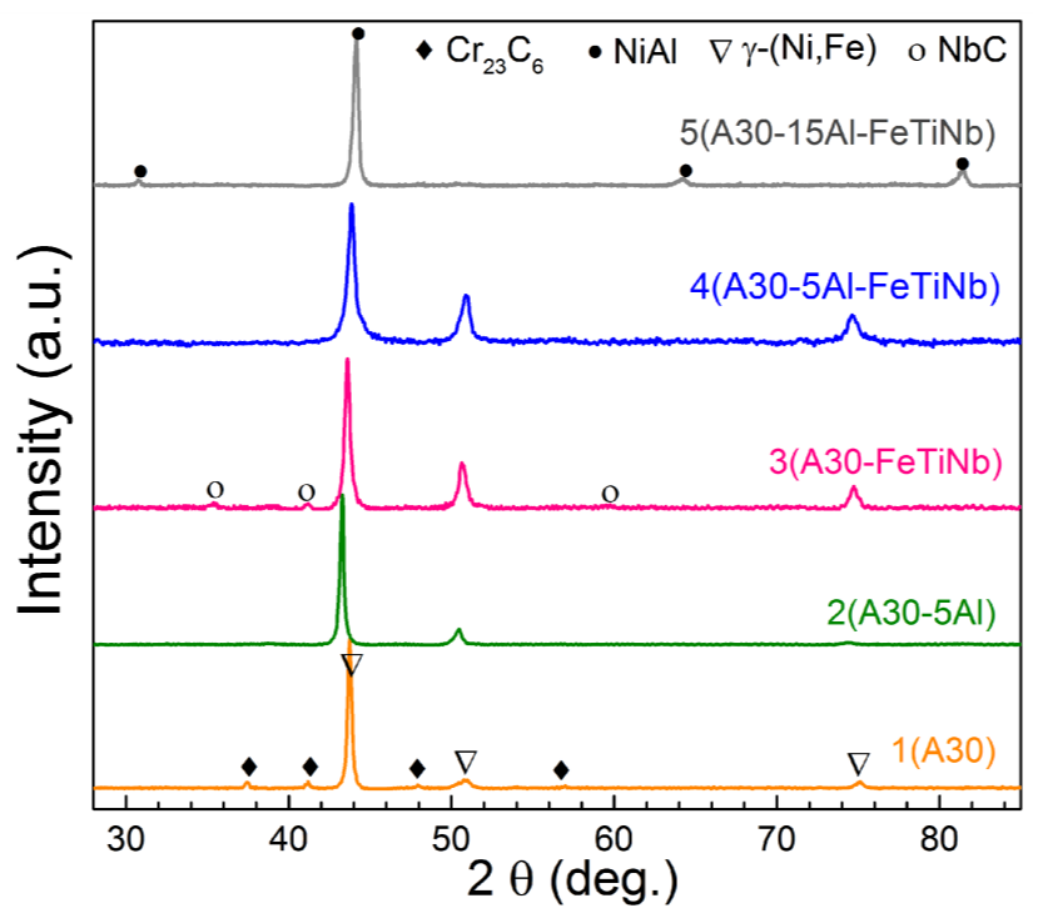

Fig. 2 XRD patterns of the cast alloys 

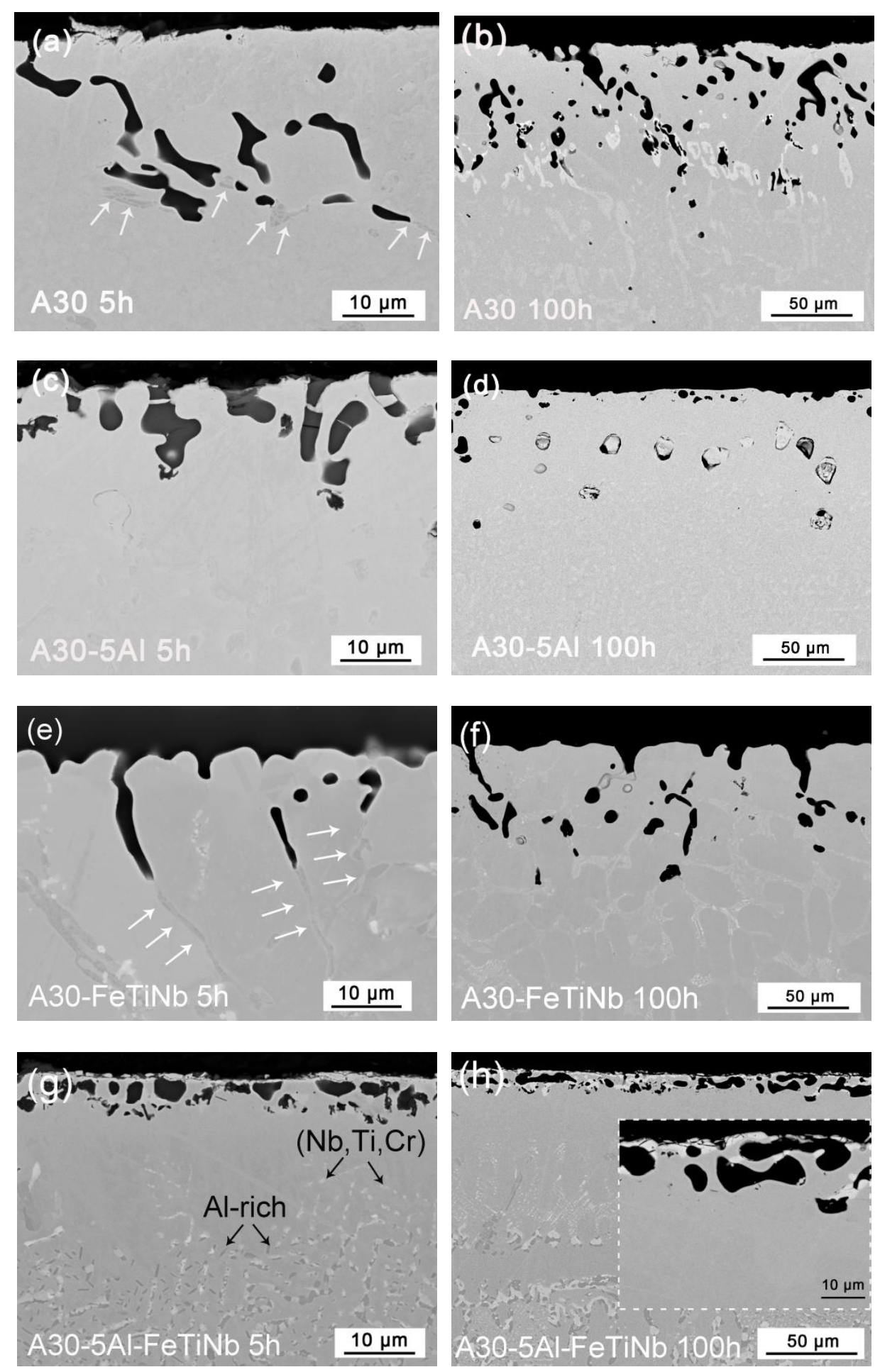


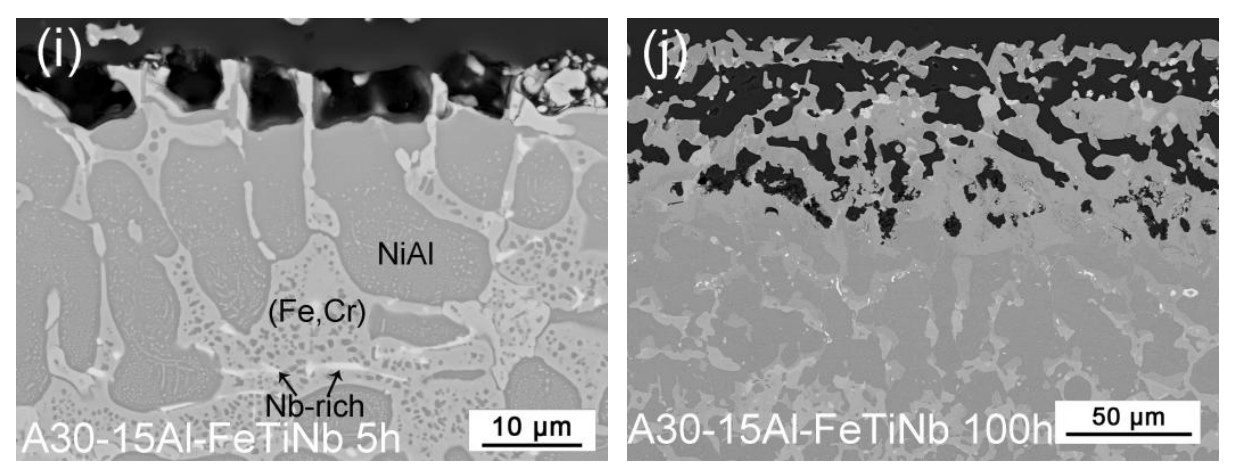

Fig.3 Microstrutures of alloys after immersion in molten glass at $1050{ }^{\circ} \mathrm{C}$ for $5 \mathrm{~h}$ and $100 \mathrm{~h}$ : (a,b) Alloy 1, (c,d) Alloy 2, (e,f) Alloy 3, (g,h) Alloy 4, (i, j) Alloy 5 


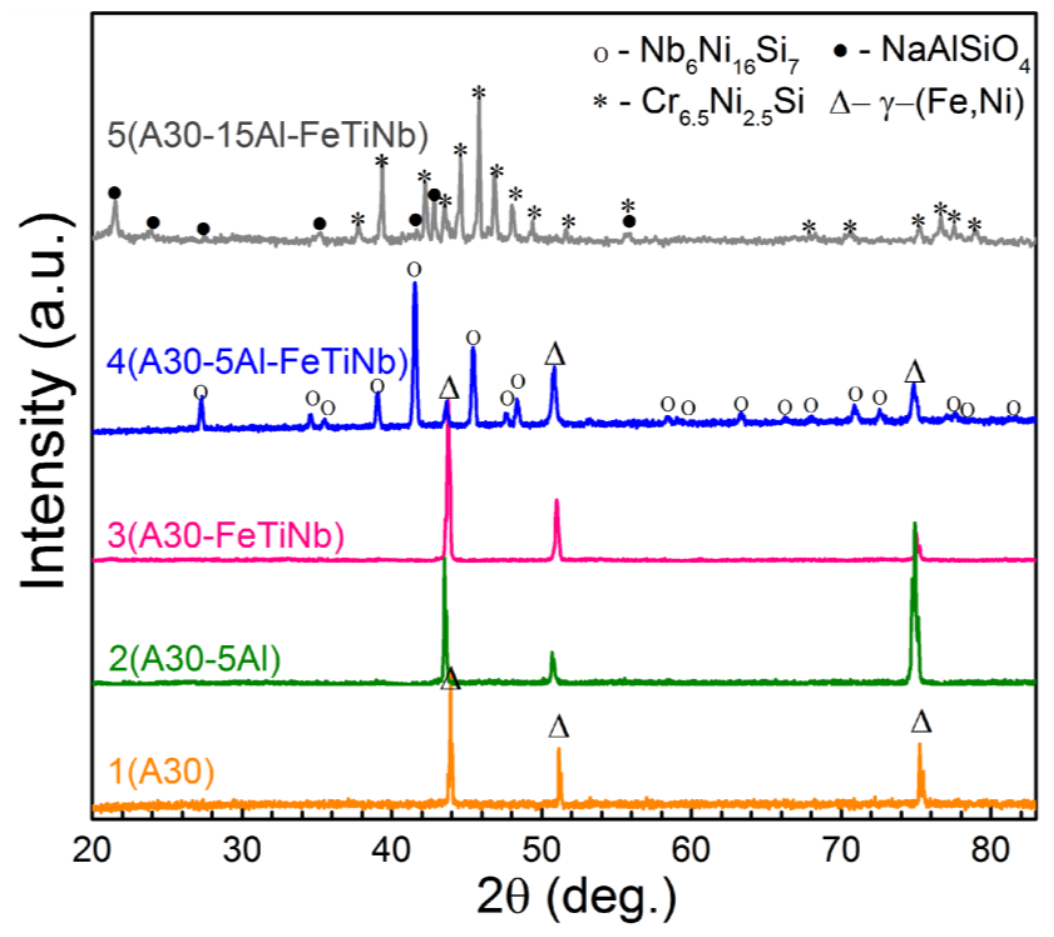

Fig. 4 XRD patterns of alloys after molten glass corrosion at $1050{ }^{\circ} \mathrm{C}$ for $100 \mathrm{~h}$ 




Fig. 5 EPMA mapping results of Alloy 1 after molten glass corrosion at $1050{ }^{\circ} \mathrm{C}$ for $100 \mathrm{~h}$ 


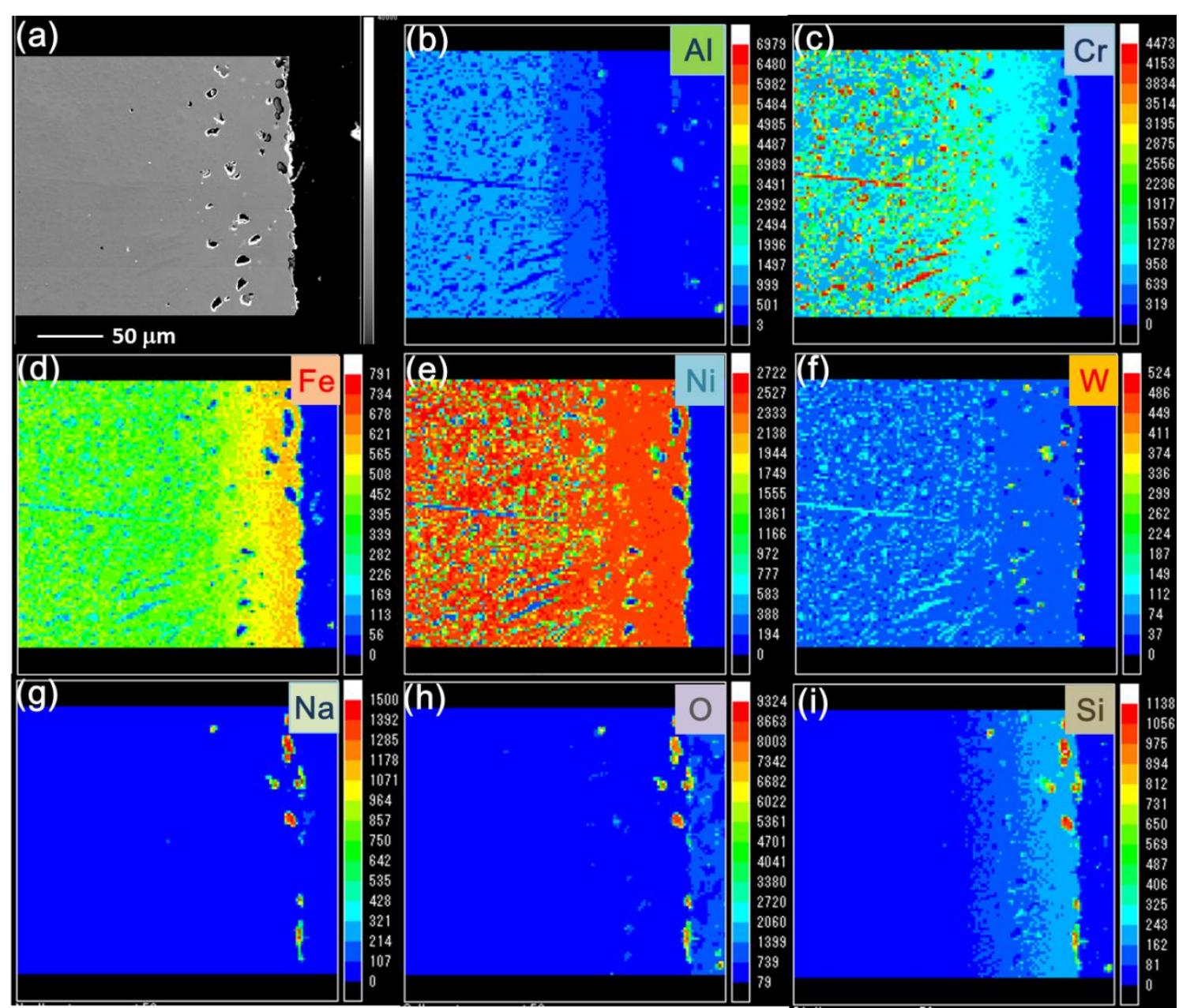

Fig. 6 EPMA mapping results of Alloy 2 after molten glass corrosion at $1050{ }^{\circ} \mathrm{C}$ for $100 \mathrm{~h}$ 


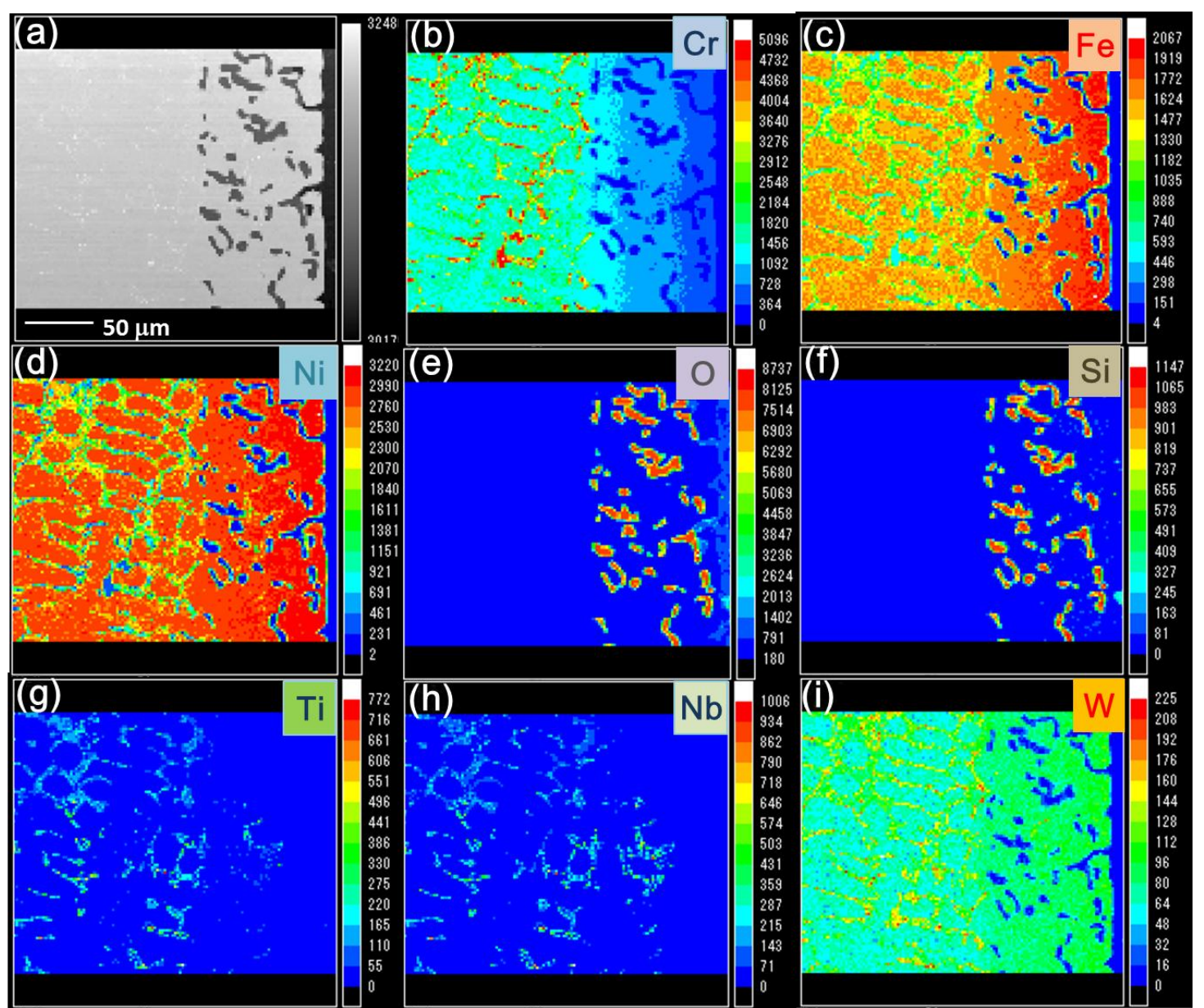

Fig. 7 EPMA mapping results of Alloy 3 after molten glass corrosion at $1050{ }^{\circ} \mathrm{C}$ for $100 \mathrm{~h}$ 


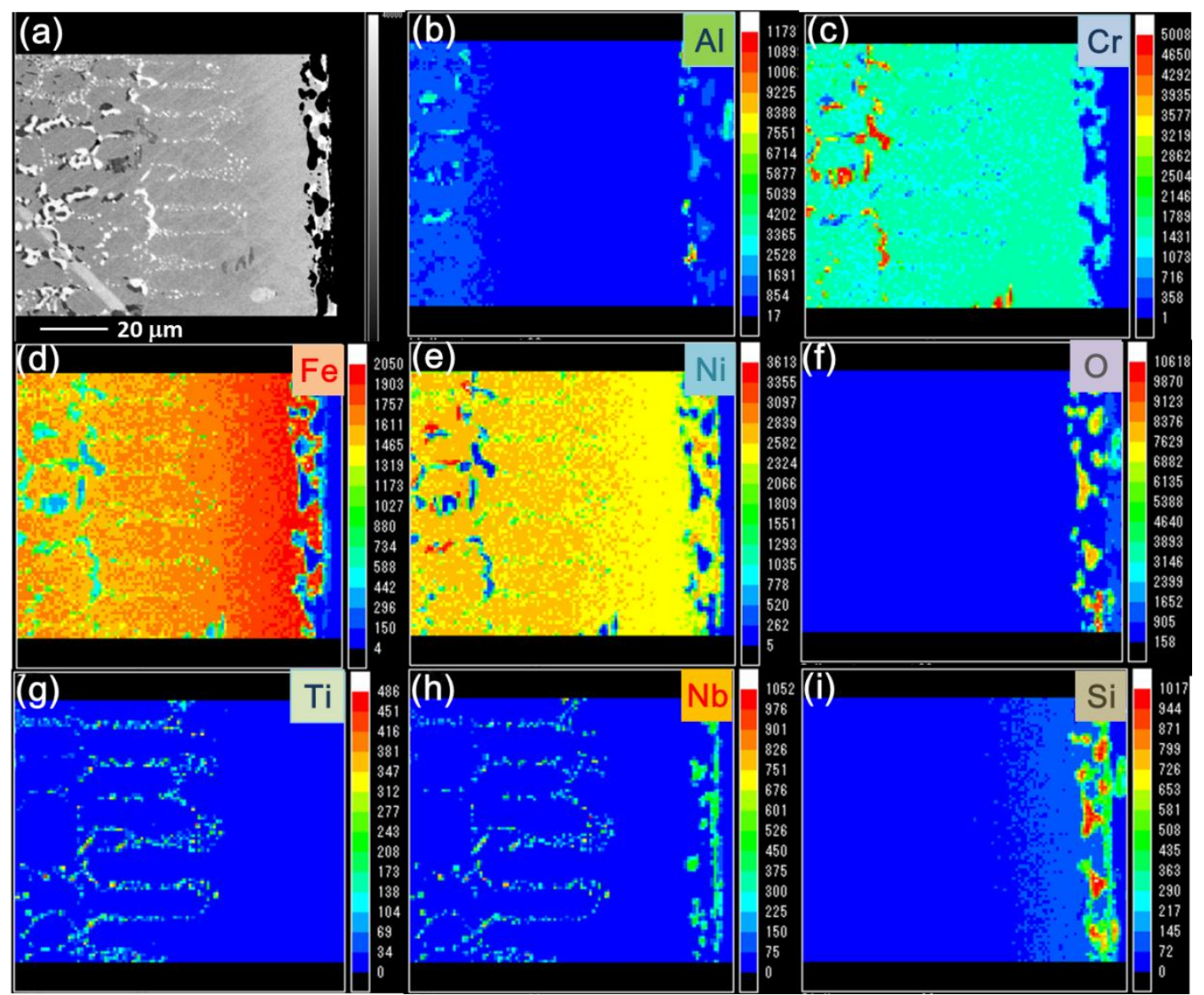

Fig. 8 EPMA mapping results of Alloy 4 after molten glass corrosion at $1050{ }^{\circ} \mathrm{C}$ for $100 \mathrm{~h}$ 


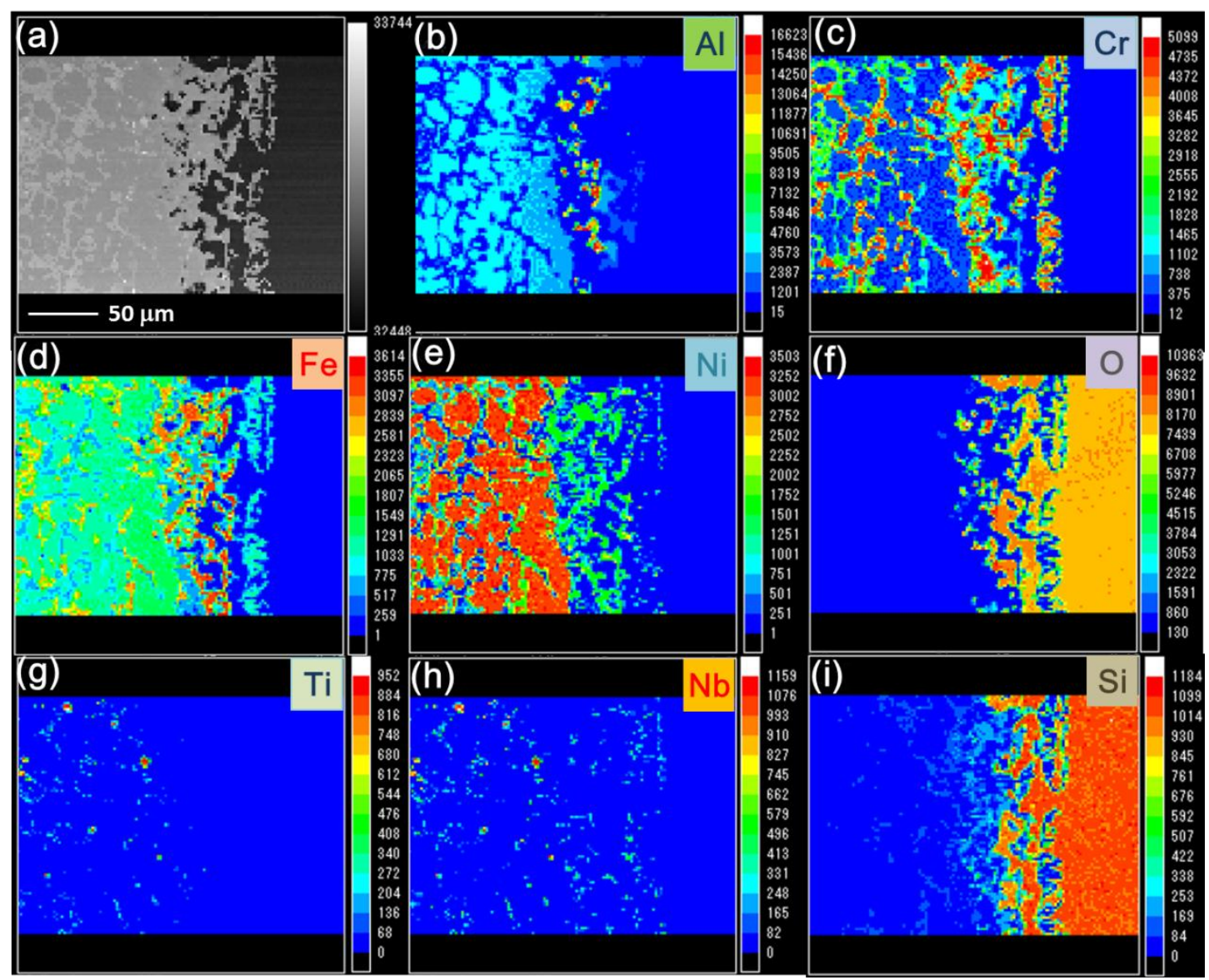

Fig. 9 EPMA mapping results of Alloy 5 after molten glass corrosion at $1050{ }^{\circ} \mathrm{C}$ for $100 \mathrm{~h}$ 
(a)
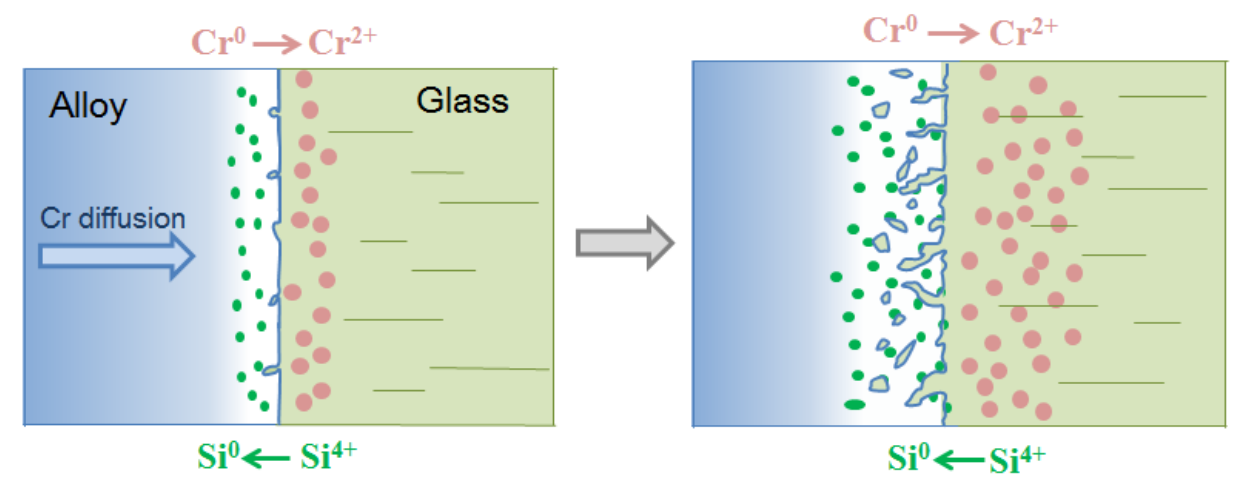

(b)
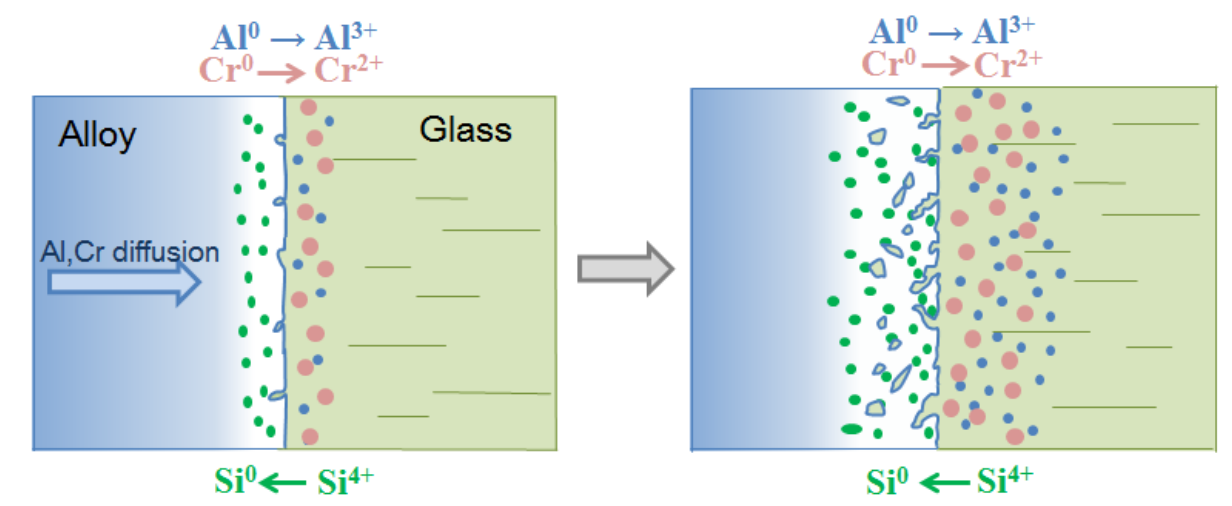

(c)
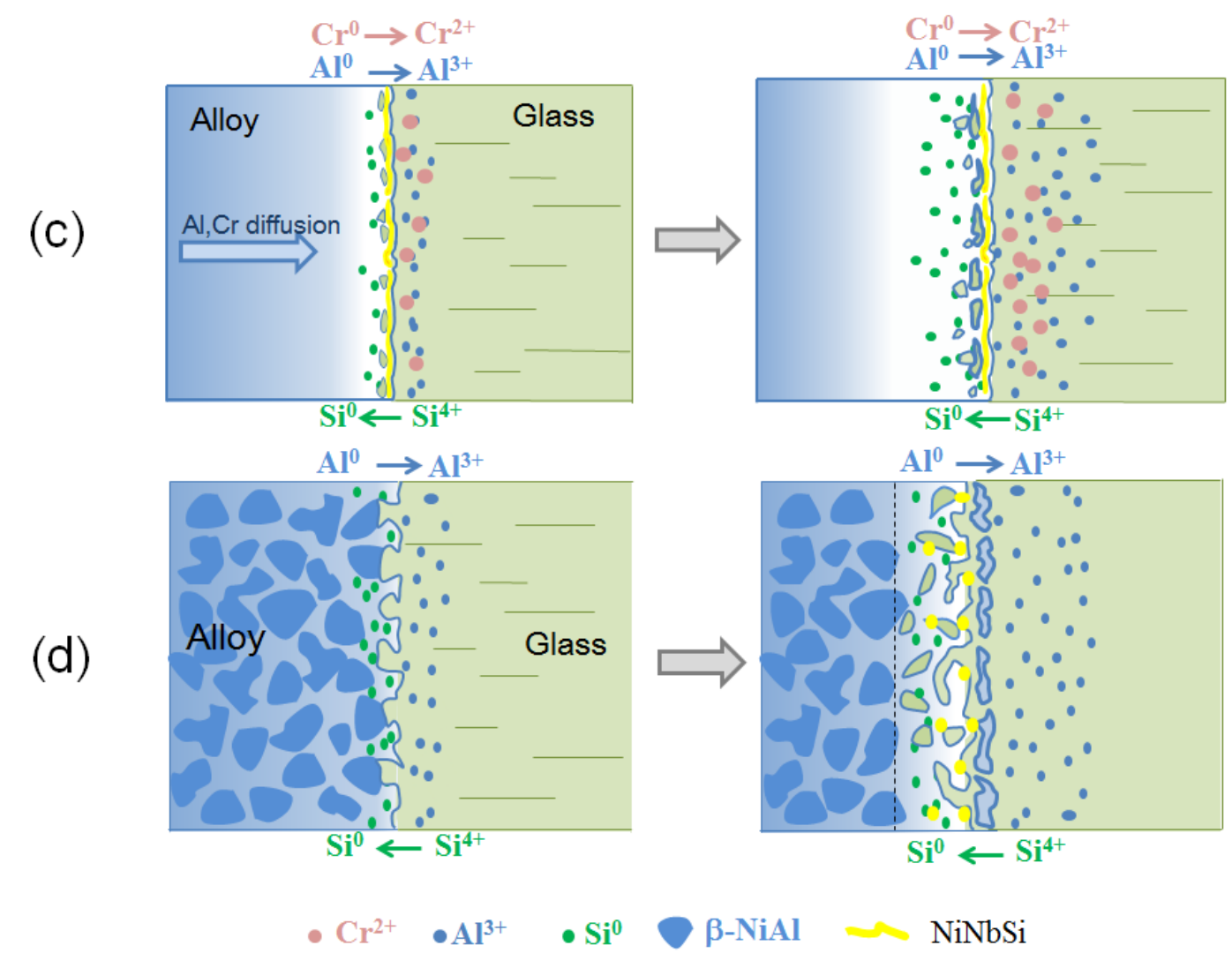

$\beta-N i A l$

$\mathrm{NiNbSi}$

Fig. 10 Schematic diagrams of corrosion mechanism for Ni-Cr alloys: (a) without Al; (b) with low levels of $\mathrm{Al}$ (5 wt.\%); (c) with 5 wt.\% $\mathrm{Al}$ and FeTiNb; (d) with 15 wt.\% $\mathrm{Al}$ and FeTiNb 